\title{
When and why do individuals craft their jobs? The role of individual motivation and work characteristics for job crafting
}

\section{Cornelia Niessen}

Friedrich-Alexander-University of Erlangen-Nürnberg, Germany

\section{Daniela Weseler}

Friedrich-Alexander-University of Erlangen-Nürnberg, Germany

\section{Petya Kostova}

University of Konstanz, Germany

\begin{abstract}
As a proactive behavior, job crafting refers to changes in the task (cognitive, and behavioral) and social boundaries at work. This article focuses on antecedents of job crafting and the development and validation of a job crafting scale. In Study I $(N=466)$, an exploratory factor analysis with one half of the sample $(n=233)$ and a confirmatory factor analysis with the other half $(n=233)$ supported a three-dimensional structure of job crafting (task crafting, relational crafting and cognitive crafting), and convergent as well as discriminant validity of job crafting, in relation to personal initiative and organizational citizenship behavior. In Study 2 ( $N=118$, two points of measurement), we crossvalidated the measure and demonstrated that job crafting was related to, yet distinct from, taking charge. We found that an increase in job crafting at Time 2 was predicted by need for positive self-image (Time I), as well as by work experience (Time I). Need for human connection (Time I) was related to job crafting at Time 2 when self-efficacy was high. Moreover, there was evidence that job crafting as self-oriented behavior related positively to person-job fit. Implications for future research are discussed.
\end{abstract}

\section{Corresponding author:}

Cornelia Niessen, Institute of Psychology, Friedrich-Alexander-University of Erlangen-Nürnberg,

Nägelsbachstr. 49c Erlangen 91052, Germany.

Email: cornelia.niessen@fau.de 


\section{Keywords}

job crafting, needs, proactive behavior, scale development, self, self-efficacy, work characteristics

Jobs are not only designed by organizations according to their requirements, but are also actively redesigned by their job holders. The process of shaping jobs so that tasks and social interactions better suit an individual's needs, abilities and preferences has been called job crafting by Wrzesniewski and Dutton (2001; see also Berg et al., 2010b). Hence, job crafting is a kind of self-oriented proactive behavior (Belschak and Den Hartog, 2010; Crant, 2000; Grant and Ashford, 2008; Parker et al., 2010) with which individuals improve their fit with their job, revise the meaning of their work and change their work identity. Recently, job crafting has received increased attention in organizational research. Qualitative studies have explored job crafting activities for different jobs (e.g. Berg et al., 2010a, 2010b; Sturges, 2012), and results from quantitative field studies have revealed that individuals who craft their jobs are more motivated to accomplish their work, show more work engagement (Petrou et al., 2012; Tims et al., 2013b), perform better, thrive (e.g. Bakker et al., 2012; Leana et al., 2009; Tims et al., 2012), and experience higher levels of well-being (Nielsen and Abildgaard, 2012; Slemp and Vella-Brodrick, 2014; Tims et al., 2013). Although some studies have shown that job crafting has positive effects for individuals and organizations, its antecedents are not well understood (Bakker et al., 2012; Lyons, 2008). Therefore, the present article had two main objectives. First, we aimed to identify antecedents of job crafting. Second, we developed and validated a job crafting scale that emphasizes the self-oriented nature of job crafting and measures self-initiated changes of tasks (task crafting), social relationships (relational crafting), as well as changes in the perception of one's own job (i.e. cognitive crafting) in daily working life as well as during organizational change.

The article contributes to research on job crafting in at least two ways. First, it expands previous research on job crafting by examining why individuals craft their jobs. Thus, we focused not only on work characteristics (autonomy, task interdependence), and on individual differences (work experience), but also on motivational states (self-efficacy, needs) that relate to job crafting. Until now, we have only had limited empirical evidence about what motivates individuals to craft their jobs. Second, we developed and validated a job crafting scale put forth by Wrzesniewski and Dutton (2001), which explicitly addresses the self-oriented nature of job crafting, the unique feature of job crafting.

\section{Job crafting}

Job crafting is a proactive behavior, in that individuals take an active role in their approach toward their work, initiate future-oriented actions, and create favorable conditions (Bindl and Parker, 2011; Crant, 2000; Grant and Ashford, 2008; Parker et al., 2010). Wzresniewski and Dutton (2001) propose that employees can change formerly constructed job roles by changing task and relational boundaries of the job in order to change work meaning and work identity. They specify three job crafting activities, namely task 
crafting, relational crafting and cognitive crafting. Task crafting involves employees actively molding the tasks they have to fulfill at work by taking on more or fewer tasks, by altering the scope of the tasks, and by changing the means of task accomplishment. Relational crafting refers to the change of the quality and/or amount of interactions with others at work. Employees decide upon who they will interact with more or less intensively while doing the job. Cognitive crafting comprises reframing how employees perceive their job and altering their cognitive representation of the job (e.g. a 'hospital cleaner seeing her work as a means to help people rather than simply cleaning' (Berg, Dutton, \& Wrzesniewski, 2008: 1).

Wrzesniewski and Dutton (2001) illustrated the phenomenon job crafting and built their theoretical framework mainly on the basis of qualitative studies. Their seminal article also stimulated quantitative research and the development of context-specific measurement scales (for teaching in schools, manufacturing, e.g. Ghitulescu, 2006; child-care, e.g. Leana et al., 2009), and context-independent measurement scales (e.g. Tims et al., 2012) that could be generalized to different types of work. Here, the most common scale is the job crafting measure of Tims et al. (2012), which distinguishes between changing job demands (challenging and hindering demands), and changing job resources (social and structural resources). Nielsen and Abildgaard (2012) adapted this scale to measure job crafting of blue-collar workers, and Petrou et al. (2012) adapted the scale to measure crafting on a daily basis.

In line with Wrzesniewski and Dutton (2001), Tims et al. (2012) emphasized that jobholders initiate a bottom-up redesign. Thereby, the crafting behavior of changing job demands can be linked to task crafting, and changing job resources can be linked to relational crafting (Demerouti, 2014). Despite these similarities, both conceptualizations view job crafting from different perspectives. Tims et al. (2012) built their conceptualization on the job demand-resources model (JD-R) and proposed that individuals strive for a more suitable, meaningful, engaging and satisfying job, but also for the protection of their own health. In this latter case, job crafting is a kind of active coping with stress at work. In Wrzeniewski and Dutton's (2001) conceptualization of job crafting, individuals align their work with their individual needs and values to find personal meaning. Thus, compared with Tims et al. (2012), the main source and target of job crafting according to the approach of Wrzeniewski and Dutton - is the self. This also includes crafting the job cognitively so that it is suited better to oneself.

Cognitive crafting as a job crafting activity is seen as controversial. Tims and Bakker (2010) argued that cognitive crafting is more a kind of avoidance coping because individuals do not really shape their jobs but rather adjust their perspective on those work conditions that do not fit with their needs, abilities and preferences. We think that cognitive crafting is an important proactive strategy for achieving fit with the work environment through changing the meaning of work and work identities. Action identification theory (Vallacher and Wegner, 1987) states that individuals represent their actions on different levels in a cognitive hierarchy that guide how an individual engages in an action. Actions can be represented on a lower level (e.g. wiping the patients' rooms), but also on a higher, more comprehensive level, indicating why and with what effect the action is performed (e.g. helping patients). By representing an action on a higher level, it is more likely that individuals focus more on events and characteristics of their job that 
fit with their self, their needs, abilities and preferences, and recognize opportunities at work to behave and act in accordance with their perspective of the job. For example, the abovementioned hospital cleaner who sees her work as a means to help might start to intensify contacts with nurses and patients (Wrzesniewski and Dutton, 2001).

We followed the conceptualization of Wrzesniewki and Dutton (2001), and developed a measure, which included task, relational and cognitive crafting. This measure adds two significant aspects to the construct of job crafting that go beyond the general measure developed recently by Tims et al. (2012). First, we emphasize the self-oriented nature of job crafting by asking whether individuals engage in crafting behaviors so that the job suits them. Tims et al. (2012) ask participants, for example, whether they engage in behaviors such as seeking feedback and advice from colleagues. This makes it difficult to distinguish crafting behaviors from other proactive behaviors, such as feedback seeking (e.g. Ashford and Black, 1996). Second, we also assessed cognitive crafting because of the abovementioned reasons.

We examined whether our job crafting measure is related to - yet empirically distinct from - proactive behaviors, including personal initiative, but also from taking charge and extra-role behaviors, such as organizational citizenship behavior. Personal initiative is defined as self-starting behavior that goes beyond formal job requirements, but serves organizational goals (Frese et al., 1997). Individuals who show personal initiative start activities by themselves that have a long-term focus and are future-oriented. They solve problems and are persistent when obstacles and barriers occur. Job crafting is distinct from personal initiative in that it serves organizational goals to a lesser extent, and is less focused on problem solving (Wrzesniewski and Dutton, 2001). Another related concept - taking charge (Morrison and Phelps, 1999) - is even more focused than personal initiative on self-starting problem-solving behaviors that improve how work is executed. Again, job crafting should relate to taking charge because both concepts share the selfstarting, future-oriented dimension. But taking charge is distinct from job crafting because it is used to increase organizational effectiveness rather than to alter meaning and work identity. Organizational citizenship comprises behaviors aimed at supporting either others at work or the organization itself. This includes behaviors reflecting altruism, courtesy, sportingness and civic virtue (Organ, 1988). As all types of job crafting are aimed at gaining meaning at work that is independent of the usefulness of this behavior for colleagues, supervisors or the entire organization, it should be related to - but distinct from - organizational citizenship behavior. Thus, we proposed the following hypothesis:

Hypothesis 1: Job crafting (task crafting, relational crafting and cognitive crafting) is positively related to, yet distinct from, (a) personal initiative, (b) taking charge and (c) organizational citizenship behavior.

In addition to the test of convergent and discriminant validity, we also examined the criterion-related validity of the job crafting scale used in this study. Individuals craft their jobs because they aim at adapting their job to their needs and preferences (Berg et al., 2010b; Wrzesniewski and Dutton, 2001). Lu et al. (2014) already showed that crafting work characteristics was related to an increase in the demands-abilities fit whereas 
relational crafting was related to the needs-supplies fit. It seems also likely that task crafting is related to the needs-supplies fit: Individuals might satisfy their needs (i.e. need for competence) by choosing tasks that provide opportunities to utilize their skills. In addition, we assume that cognitive crafting relates positively to needs-supplies fit. By representing tasks at work in a different manner, individuals might focus on features of their job that fit with their needs. Thus, we proposed the following hypothesis:

Hypothesis 2: (a) Task crafting, (b) relational crafting and (c) cognitive crafting relate positively to the perceived needs-supplies fit.

\section{Antecedents of job crafting}

We propose differential relationships between motivational factors, work characteristics, and work experience with the three forms of job crafting (see Figure 1).

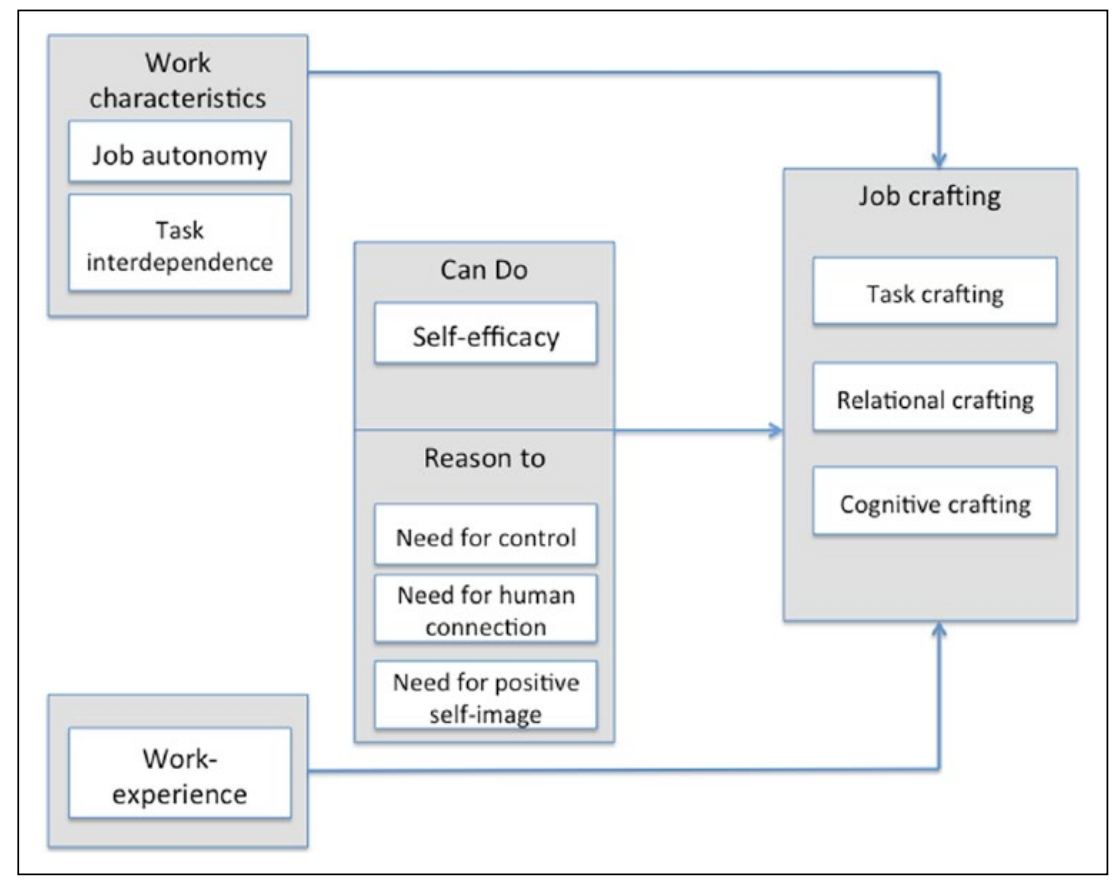

Figure I. Conceptual model of antecedents of job crafting.

\section{Motivational factors}

In their model of proactive behavior, Parker et al. (2010) proposed three motivational states that predict proactive behavior: can do, reason to and energized to factors. Whereas reason to factors shed light on the question of why individuals engage in proactive 
behaviors, can do factors are subjective assessments of being capable of proactivity, and energized to factors refer to activated positive affect. For our research purpose, we focused on can do and reason to factors. The can do factor we investigated was selfefficacy; the belief that one is capable of accomplishing particular tasks (Gist and Mitchell, 1992). As individuals with high self-efficacy and who experience control are more persistent in tasks despite setbacks, and have higher expectations that they will succeed, they engage more in proactive behaviors (Parker et al., 2006), show more personal initiative (Speier and Frese, 1997), take charge more often (Morrison and Phelps, 1999), and engage in voice behaviors more often (Withey and Cooper, 1989). Ohly and Fritz (2007) found a positive relationship between role-related self-efficacy and proactive behavior. Parker et al. (2010) argued that self-efficacy relates positively to proactive behavior because when individuals believe they will be successful, they are willing to take the psychological risk of engaging in proactive behaviors. This might also be true for job crafting. Recently, Tims et al. (2014) showed in a diary study that individuals who felt self-effective searched for more opportunities to learn new things and sought more variety in tasks. Consequently, it seems likely that individuals with a higher level of selfefficacy craft their jobs, especially by taking on new tasks:

\section{Hypothesis 3: Self-efficacy is positively related to task crafting.}

In addition to this can do factor, we investigated why individuals engage in job crafting (reason to factors, Parker et al., 2010). Specifically, we examined Wrzesniewski and Dutton's (2001) proposed - but not yet empirically supported - role of need for control, need for positive self-image and need for human connection. Many theorists propose that gaining control is a basic human need (e.g. Burger and Cooper, 1979), which reflects the degree to which individuals are motivated to manipulate, in a desired direction, the events in their life (Burger and Cooper, 1979). Control perceptions positively affect psychological well-being (e.g. Greenberger et al., 1989), predict personal initiative (Fay and Frese, 2001) and proactive socialization tactics, such as information seeking, socializing and networking (Ashford and Black, 1996). In their study with newcomers, Ashford and Black (1996) also found that desire for control predicted job change negotiation, referring to intended changes of task objectives, methods, materials, scheduling and also interpersonal relationships. Desire for control was also related to seeking out and building new relationships at work. Building on these results, we assumed that with task crafting as well as with relational crafting, individuals make the work environment more predictable for themselves (Black and Ashford, 1995). In addition, Ashford and Black (1996) examined positive framing of events, which is similar to the concept of cognitive crafting proposed by Wrzesniewski and Dutton (2001). Ashford and Black (1996) showed that individuals with a high need for control cognitively reframed situations more positively. Thus, we assume that the need for control stimulates cognitive crafting:

Hypothesis 4: Need for control is positively related to (a) task crafting, (b) relational crafting and (c) cognitive crafting. 
The need for human connection - or the need for belonging - is fundamental for human beings. This need refers to the motivation to build relationships with others as a way to introduce meaning into life (Baumeister and Leary, 1995). Individuals with a high need for human connection are motivated to invest time and energy in their connection with others, are more dependent on others, and are more responsive toward social acceptance or rejection (Baumeister and Leary, 1995; Gardner et al., 2000; Rego et al., 2009; Sheldon and Gunz, 2009). Moreover, individuals with a high need for human connection experience social relationships as a source of social and emotional resources (Rego et al., 2009). Therefore, it seems likely that individuals with a high need for human connection craft the social boundaries of their work:

Hypothesis 5: Need for human connection is positively related to relational crafting.

The theory of self-enhancement states that individuals have a basic need to sustain and create a positive sense of self (e.g. Leary, 2007). Research supports the notion that individuals are motivated to strive for a positive self-image (Swann and Bosson, 2010). Wrzeniewski and Dutton (2001) argued that the need for positive self-image positively predicts job crafting activities. This might be true for the following reasons. First, individuals who try to maximize the positivity of their self-view might identify discrepancies between their self-view and their valued goals or work identity. This might motivate them to craft the cognitive, task and social boundaries at work according to their values and priorities. Second, self-verification theory (Swann and Read, 1981) states that individuals prefer a social environment that is coherent and predictable, and which allows them to reassure their self-view through social interactions. Individuals want others to see them as they see themselves (Swann and Bosson, 2010). Therefore, it is likely that individuals craft task and social boundaries of their work. When in interaction with others, individuals gain a significant evaluation of their competencies, the value of their work, and their work role. In a similar vein, individuals might also engage in cognitive crafting. To maintain their positive self-image, they change their view of work so that it better fits with their valued goals and work identity (Ashforth and Kreiner, 1999). We proposed the following hypothesis:

Hypothesis 6: Need for positive self-image is positively related to (a) task crafting, (b) relational crafting and (c) cognitive crafting.

\section{Distal antecedents: Work characteristics and work experience}

We propose that work characteristics such as job autonomy and task interdependence should provide opportunities for job crafting. The model of job crafting by Wrzesniewski and Dutton (2001), as well as the model of proactive behavior by Parker et al. (2010), portray job autonomy as an important prerequisite of proactive behaviors. Hackman and Oldham (1976) defined job autonomy as 'the degree to which the job provides substantial freedom, independence, and discretion to the individual in scheduling the work and 
in determining the procedures used in carrying [it] out' (p. 257). A high level of job autonomy is generally thought to be beneficial at work (Humphrey et al., 2007), and studies have demonstrated that increased autonomy is positively associated with proactive behavior and personal initiative (Frese et al., 1996; Ghitulescu, 2013; Hornung and Rousseau, 2007). According to the model by Wrzesniewski and Dutton (2001), high job autonomy should provide opportunities to reflect about the job and/or to effectively change task and social boundaries. Research has revealed that high job autonomy relates positively to motivation (Humphrey et al., 2007). In addition, increasing autonomy means giving individuals more freedom to determine their work procedures and to schedule their tasks (Hackman and Oldham, 1976), which stimulates them to rethink their work, and makes it more likely that they alter their cognitive representation of their job. Based on this, the following hypothesis was stated:

Hypothesis 7: Job autonomy relates positively to (a) task crafting, (b) relational crafting and (c) cognitive crafting.

Wrzesniewski and Dutton (2001) also proposed that work characteristics, such as task interdependence, should hinder job crafting. Task interdependence refers to the extent to which tasks or work processes are interrelated (Scott, 1987). Thus, when individuals aim to craft their jobs on the task level, they might anticipate that the planned changes affect the timing of work processes or the accomplishment of colleagues' tasks. This might restrict the degree of possible task alterations, and might demotivate one to think about their own job in a more meaningful way. Moreover, task interdependence might restrict opportunities to craft social boundaries at work because it determines, to a certain degree, which individuals work together. Therefore, we proposed the following hypothesis:

Hypothesis 8: Task interdependence negatively relates to (a) task crafting, (b) relational crafting and (c) cognitive crafting.

As an additional distal antecedent, we examined work experience. Studies have shown that the length of experience is consistently and positively related to the level of job knowledge (Schmidt et al., 1986). In this article, we focused on the number of years an employee worked in an organization. Thus, it seems likely that when individuals stay in one organization for a longer time, they develop knowledge about work processes, organizational arrangements, and the social system, vision and physical setting of the organization (McDonald, 2011; Porras and Robertson, 1992). We propose that knowledge about an organization is a prerequisite for job crafting for several reasons. First, experienced employees might have more knowledge about workflow and work processes, and therefore more realistic expectations about which job crafting activities are possible without creating negative side effects for coworkers or supervisors. This makes it more likely that individuals actually craft their tasks. In addition, gaining more knowledge about the organization, as one's own job fits into the big picture, might alter the perception and the cognitive representation of the job (cognitive crafting). Second, as individuals gain experience, they accumulate skills, but they also accumulate social 
contacts in an organization. These contacts help to perform tasks, and provide opportunities as well as formal and informal work-related information, which might facilitate relational crafting. Insight into the social system of an organization might be a prerequisite to deciding upon with whom an individual wants to interact with more or less intensively while doing the job. Third, employees who are familiar with the organization are also aware of others expectations, and know what they might expect in the future. This might stimulate reflection about one's job as well as questions about what is missing in the job, a prerequisite to alter their cognitive representation of the job. We stated the following hypothesis:

Hypothesis 9: Work experience is positively related to (a) task crafting, (b) relational crafting and (c) cognitive crafting.

\section{Method}

We conducted two empirical studies. In Study 1, we tested the construct validity of our measure. In Study 2, we cross-validated this measure and tested our hypotheses.

\section{Samples and procedures}

Sample and procedure of Study I. We collected our data in conjunction with a provider of online surveys (respondi AG; for studies with comparable recruiting, see also Hahn and Dormann, 2013; Neff et al., 2013). Participation was voluntary, and rewarded with credit points, which could be exchanged for gift vouchers at a later time. We introduced the study as a survey on 'Vitality and Flexibility at the Workplace.' As a precondition for participating in the survey, individuals had to work full time, and at the time of the survey had to be experiencing organizational change. We assumed that job crafting might be more likely to occur in the context of organizational change because when tasks and roles change, job crafting activities might be stimulated (Petrou et al., 2012; Van den Heuvel et al., 2010). In total, 466 out of 886 recruited employees met our criteria for participation and completed the questionnaire (53\% response rate). Participants' mean age was 40.28 years (standard deviation $[\mathrm{SD}]=10.82), 44.4$ percent of the participants were female and 41 percent had a leadership position. Participants worked an average of 41.45 hours per week $(\mathrm{SD}=5.58)$. Mean organizational tenure was 10.38 years $(\mathrm{SD}=8.98)$. The sample was diverse in terms of industries (37.5\% community, social service, education; $26.7 \%$ business and financial operations; $14.5 \%$ production; $12.2 \%$ sales and related; $3.0 \%$ construction and extraction; $1.5 \%$ food preparation and service related; $4.3 \%$ other).

Sample and procedure of Study 2. To recruit study participants, we approached German human resources managers and employees in diverse industries via professional networking sites. We introduced the study as research on 'Work Design and Work Satisfaction,' and assured our participants that their responses would remain confidential. To be included in the study, participants had to be employed and had to work at least 20 hours a week. Participants were asked to fill out two online questionnaires within two weeks. For study participation, we raffled three $€ 50$ vouchers among the participants. 
One hundred and fifty employees agreed to participate in the study, and 137 employees $(90.7 \%)$ finished the first questionnaire. At Time 2, 127 employees filled out the second questionnaire $(92.7 \%)$. In total, the final sample comprised 118 employees in a variety of industries $(20.3 \%$ community, social service, education; $52.5 \%$ business and financial operations; $6.8 \%$ production; $13.6 \%$ sales and related; $3.4 \%$ construction and extraction; $1.7 \%$ food preparation and service related; $1.7 \%$ other) who provided two complete data sets. Mean age was 36.86 years $(\mathrm{SD}=9.25), 42$ percent were female and 38.1 percent had a leadership position. Mean professional experience was 15.5 years (SD $=10.41)$, mean organizational tenure was 6.67 years $(\mathrm{SD}=7.34)$.

\section{Measures}

Job crafting. The final scale comprised nine items (three items each for task crafting, relational crafting and cognitive crafting). We instructed the participants to rate job crafting activities on a five-point scale from $1=$ Not At All to $5=$ Absolutely. Because job crafting is conceptualized as a self-oriented proactive behavior (Wrzesniewski and Dutton, 2001), we asked our participants to respond to 'so that the job I do suits me...' (for items see Table 6). In Study 1 (second half of the sample, $n=233$ ), Cronbach's alpha for the composite measure of job crafting was .86, for task crafting .79, for relational crafting .75, and for cognitive crafting .81. In Study 2, Cronbach's alpha was .72, .72, .71 and .71 for the composite measure, task crafting, relational crafting and cognitive crafting, respectively at Time 1 (T1), and .72, .58, .73 and .71 for the composite measure, task crafting, relational crafting and cognitive crafting, respectively at Time 2 (T2).

\section{Measures in Study I}

Personal initiative. Personal initiative was assessed with the scale of Frese et al. (1997) with all items using response anchors of $1=$ Not At All to $5=$ A Great Deal. Sample items included the following: 'I actively attack problems.' Cronbach's alpha was .88 .

Organizational citizenship behavior. Organizational citizenship behavior was measured with the helping subscale of Staufenbiel and Hartz (2000). The response scale ranged from $1=$ Not At All to $7=$ A Great Deal. A sample item was: 'I take the initiative to help new colleagues during organizational socialization.’ Reliability was .86 .

\section{Measures in Study 2}

Taking charge. We assessed taking charge at Time 1 with the scale of Morrison and Phelps (1999). The items used response anchors of $1=$ Strongly Disagree to $5=$ Strongly Agree. A sample item was: 'I often try to adopt improved procedures for doing my job.' Reliability was .79.

Fit perceptions. Respondents were asked to indicate on five-point scales, ranging from $1=$ Not At All to $5=A$ Great Deal, how well they perceived their fit with their current work demands. We used the scale of Cable and DeRue (2002) to measure the 
perceived needs-supply fit. A sample item was: 'There is a good fit between what my job offers me and what I am looking for in a job.' Coefficient alpha was .93 at Time 1 and .94 at Time 2.

Self-efficacy. At Time 1, self-efficacy was measured with the scale of Chen et al. (2001). A sample item was: 'I believe I can succeed at most any endeavor to which I set my mind.' The response scale ranged from $1=$ Not At All to $5=A$ Great Deal. Reliability was .85.

Need for control. We measured need for control at Time 1 with the subscale 'desired control' from the control-scale of Greenberger (1981) using response anchors of $1=$ Not At All to $5=$ A Great Deal. A sample item was: 'How much influence would you like to have over the variety of tasks you perform?' Cronbach's alpha was .85 .

Need for human connections. The need to belong scale of Leary et al. (2006) was used to measure the need for human connections at Time 1, using response anchors of $1=$ Strongly Disagree to $5=$ Strongly Agree. A sample item was: 'I want other people to accept me.' Cronbach's alpha was .78.

Need for positive self-image. We chose the self-liking scale of Tafarodi and Swann (2001) to assess the need for positive self-image at Time 1 . The response scale ranged from $1=$ Strongly Disagree to 5 = Strongly Agree. The items included the following example: 'I want to feel very comfortable with myself.' Reliability was .93.

Job autonomy. At Time 1, job autonomy was assessed with the scale of Semmer et al. (1999) using response anchors of $1=$ Not At All to $5=A$ Great Deal. The scale comprises scheduling autonomy, work method autonomy, as well as, to some extent, control over the outcome. A sample item was: 'If you look at your job as a whole, to what extent can you determine the order in which you perform individual task elements?' Cronbach's alpha was .85 .

Task interdependence. Task interdependence was measured at Time 1 with the scale of Semmer et al. (1999). Task interdependence refers to how much the work depends on others' work pace, quality of work and failures. The response scale ranged from $1=N o t$ At All to $5=$ A Great Deal. A sample item was: 'How much does your work depend on how well or poorly your colleagues perform?' Cronbach's alpha was .84 .

Work experience. Work experience was operationalized as organizational tenure. Participants were asked to report their job experience (in years) within the organization.

Control variables. In Study 2, we controlled for leadership position because previous research has shown that position in an organization relates to job crafting (Berg et al., 2010b). We also controlled for the size of the employees' department because we had a highly heterogeneous sample. It could be that larger departments provide more opportunities for job crafting (e.g. owing to increased opportunities to interact with more colleagues). 


\section{Results}

We analyzed the data of both studies to develop a scale to assess job crafting. We aimed at testing a three-dimensional factor structure reflecting task crafting, relational crafting and cognitive crafting as well as a second-order latent factor representing the higherorder construct of job crafting. We started to develop the scale by generating 16 items (task crafting: seven items; relational crafting: four items; and cognitive crafting: five items). For task crafting, we developed items that should reflect change of the number and scope of tasks, and for relational crafting we developed items that should reflect shaping the quality and number of social interactions at work. Cognitive crafting was operationalized by items that should assess how employees perceive their jobs and alter their cognitive representations of the job.

Ten psychology students with an undergraduate degree rated the content validity of these items, resulting in the exclusion of two items. The students were given definitions of the three kinds of job crafting and were asked to place each item into one of the three categories. Two items that were not sorted into the pre-defined categories by seven of 10 students were excluded from further analyses. In addition, we aimed to reduce redundancy and similar wording of the items, and dropped three additional items. In the next step, we examined the factor structure, and convergent as well as discriminant validity of the remaining 12 items. We used the sample of Study 1 as a calibration sample to find the best fitting model, and validated this solution with the sample of Study 2 (cross-validation).

\section{Scale development}

Following the two-stage process by Gerbing and Hamilton (1996; see also Hurley et al., 1997), we conducted an exploratory factor analysis (EFA) with a random half of Sample $1(n=233)$ using a principle component analysis with a varimax rotation, and then crossvalidated this factor structure in a confirmatory factor analysis (CFA) with the other half of the sample $(n=233)$. The EFA revealed a three-factor solution, and the items loaded as expected on the three factors 'task crafting,' relational crafting' and 'cognitive crafting' (see Table 1). The three factors explain 65.54 percent of the variance. There was one cross-loading between the factors 'relational crafting' and 'task crafting' (see Item 'I invest in the relationships with people whom I get along with the best').

We tested this three-factor model with CFAs using Amos (Arbuckle, 2007) with the other half of Sample $1(n=233)$. Items that had low loadings on the hypothesized factor (modification indices exceeding 25.00 and factor loadings below 0.50 ) were removed from subsequent analyses. The remaining scale comprised nine items, three items for each subscale. The confirmatory factor analysis showed a good fit $\left(\chi^{2}=38.87\right.$; degrees of freedom [d.f. $=24$; Goodness of Fit Index $[\mathrm{GFI}]=.97$; Normed Fit Index [NFI] = .96; Tucker Lewis Index $[\mathrm{TLI}]=.97$; Comparative Fit Index $[\mathrm{CFI}]=.98$; Root Mean Square Error of Approximation [RMSEA] $=.052$; Root Mean Square Residual $[\mathrm{RMR}]=.038$ ) for the three-dimensional second-order factor structure. We compared this three-dimensional factor structure with a one-factor model, and a two-factor model (see Table 2). The two-factor model combined items from the subscales 'task crafting' and 'cognitive crafting' for the 
Table I. Exploratory factor analysis of the scale items for a random half of Sample I $(n=233)$.

\begin{tabular}{llll}
\hline Items & $\begin{array}{l}\text { Task } \\
\text { crafting }\end{array}$ & $\begin{array}{l}\text { Relational } \\
\text { crafting }\end{array}$ & $\begin{array}{l}\text { Cognitive } \\
\text { crafting }\end{array}$ \\
\hline
\end{tabular}

Task crafting - $15.19 \%$ variance explained.

So that the job I do suits me ...

I concentrate on specific work tasks.

I undertake or seek for additional tasks. $\quad .82$

I work more intensively on tasks I enjoy.

Relational crafting $-39.69 \%$ variance explained.

So that the job I do suits me ...

I usually limit the amount of time I spend with people I do

not get along well with, and only contact them for things

that are absolutely necessary.

I invest in the relationships with people whom I get along with the best.

I look for opportunities to work together with people

whom I get along well with at work.

I try to avoid contact with people at work whom I do not

understand to well.

Cognitive crafting - II.00\% variance explained.

So that the job I do suits me ...

I try to look upon the tasks and responsibilities I have at

work as having a deeper meaning than is readily apparent.

I find personal meaning in my tasks and responsibilities at

work.

I see my duties and responsibilities as being 'a small cog in

a large wheel.'

I view my tasks and responsibilities as being more than just part of my job.

Note: Cross loadings less than .35 are not reported.

Table 2. Confirmatory factor analysis results for job crafting for Sample I $(n=233)$ and Sample $2(n=118)$.

\begin{tabular}{lllllllll}
\hline & $\mathrm{X}^{2}$ & d.f. & GFI & NFI & CFI & TLI & RMSEA & RMR \\
\hline Calibration sample (Sample I) & & & & & & & & \\
$\quad$ One-factor model & 226.325 & 27 & .810 & .746 & .767 & .689 & .178 & .087 \\
Two-factor model & 119.521 & 26 & .887 & .866 & .891 & .848 & .125 & .056 \\
$\quad$ Best fitting three-factor model & 38.868 & 24 & .965 & .946 & .956 & .974 & .052 & .038 \\
Cross-validation sample (Sample 2) & & & & & & & & \\
$\quad$ Time I Three-factor model & 23.701 & 24 & .959 & .914 & 1.000 & 1.000 & .000 & .041 \\
$\quad$ Time 2 Three-factor model & 25.662 & 24 & .956 & .900 & .992 & .989 & .024 & .049 \\
\hline
\end{tabular}

Note: d.f. = degrees of freedom; GFI = goodness-of-fit index; NFI = normed fit index; CFI = comparative fit index; TLI = Tucker-Lewis index; RMSEA = root mean square error of approximation; RMR = root mean square residual. 
Table 3. Means, standard deviations and correlations among the study variables (Sample I).

\begin{tabular}{llrlllllll}
\hline & $M$ & SD & I & 2 & 3 & 4 & 5 & 6 \\
\hline I & Job crafting (composite) & 3.28 & .66 & $(.86)$ & & & & & \\
2 & Task crafting & 3.30 & .83 & $.85 I^{* *}$ & $(.79)$ & & & & \\
3 & Relational crafting & 3.18 & .86 & $.792^{* *}$ & $.506^{* *}$ & $(.75)$ & & & \\
4 & Cognitive crafting & 3.37 & .77 & $.809^{* *}$ & $.586^{* *}$ & $.414^{* *}$ & $(.8 I)$ & & \\
5 & OCB & 5.23 & 1.03 & $.375^{* *}$ & $.358^{* *}$ & $.158^{*}$ & $.41 I^{* *}$ & $(.84)$ & \\
6 & Personal initiative & 3.71 & .67 & $.477^{* *}$ & $.442^{* *}$ & $.217^{*}$ & $.520^{* *}$ & $.577^{* *}$ & $(.88)$ \\
\hline
\end{tabular}

Note: Sample I $(n=466) ;+p \leqslant .10 ;{ }^{*} p \leqslant .05 ;{ }^{*} p \leqslant .01 ; M=$ mean; SD = standard deviation.

first factor, and was added as a second factor item from the subscale 'relational crafting.' Table 2 shows that the proposed three-factor solution (task crafting, relational crafting and cognitive crafting) revealed the best fit indices. Intercorrelations between the subscales and the final job crafting scale for Sample 1 are reported in Table 3. The three dimensions of job crafting were correlated, and there were substantial correlations with the composite score of job crafting.

To examine Hypotheses 1a and 1c, which proposed that job crafting is positively related to, yet distinct from, personal initiative and organizational citizenship behavior, we conducted CFAs. We modeled the three dimensions of job crafting as distinct from personal initiative and organizational citizenship behavior (Model 1), and compared this model with a model where personal initiative and organizational citizenship behavior were additional latent factors of job crafting (Model 2). The results showed that Model 1 fit better than $\operatorname{Model} 2\left(\Delta \chi^{2}=\right.$ 128.90; $\Delta$ d.f. $=1, p<.0001, n=233$ ). Correlations between the job crafting scales and personal initiative, as well as organizational citizenship behavior, were small to high, with a range of $r=.22$ to $r=.52$ for personal initiative and $r=.16$ to $r=.41$ for organizational citizenship behavior (see Table 3). Therefore, Hypotheses 1a and 1c were supported.

Next, we investigated whether job crafting as a composite, as well as the three kinds of job crafting, relate positively to perceived needs-supplies fit at Time 2 (Hypothesis 2). Job crafting as a composite (Time 1), specifically task crafting, and cognitive crafting correlated significantly with needs-supplies fit at Time $2(r=.23, .23, .32)$, relational crafting not.

In addition, we conducted a hierarchical regression analyses with the data of the second study. In the first step, we entered leadership position, department size and needs-supplies fit at Time 1. In Step 2, we entered the predictor variable/s. The results of these analyses are shown in Table 4.

Job crafting as composite measure was positively associated with perceived needssupplies fit at Time 2, even when we controlled for needs-supplies fit at Time $1(\beta=.119$, $p=.027)$. Specifically, cognitive crafting $(\beta=.124, p=.034)$ at Time 1 was positively related to needs-supplies fit at Time 2 , but task crafting $(\beta=-.016$, not significant $[\mathrm{NS}])$ and relational crafting $(\beta=.069$, NS) not, after we controlled for needs-supply fit at Time 1. In sum, Hypothesis 2 was partially supported.

We examined the factor structure of Study 1 with the cross-validation sample of Study 2 at both points of measurement. Table 2 shows a good fit for the three-dimensional 
Table 4. Prediction of need-supply fit at Time 2 by job crafting assessed at Time I (hierarchical regression analyses).

\begin{tabular}{|c|c|c|}
\hline & \multicolumn{2}{|c|}{ Need-supply fit (Time 2) } \\
\hline & $\beta$ & $\Delta R^{2}$ \\
\hline Step I & & $.677^{* * *}$ \\
\hline Leader position & .060 & \\
\hline Department size & .059 & \\
\hline Need-supply fit Time I & $.801 * * *$ & \\
\hline \multicolumn{3}{|l|}{ Step 2} \\
\hline Job crafting composite & $.119 *$ & $.014^{*}$ \\
\hline Overall $F$ & & $63.073 * *$ \\
\hline$R^{2}$ & & .691 \\
\hline Adjusted $R^{2}$ & & .680 \\
\hline Step 1 & & $.677 * * *$ \\
\hline Leader position & .060 & \\
\hline Department size & .059 & \\
\hline Need-supply fit & $.802 * * *$ & \\
\hline Step 2 & & $.025 *$ \\
\hline Task crafting Time I & -.016 & \\
\hline Relational crafting Time I & .069 & \\
\hline Cognitive crafting Time I & $.124 *$ & \\
\hline Overall $F$ & & $42.611 * * *$ \\
\hline$R^{2}$ & & .697 \\
\hline Adjusted $R^{2}$ & & .681 \\
\hline
\end{tabular}

Note: Sample $2(n=1 \mid 8)$. The $\Delta R^{2}$ and $F$ values were derived from hierarchical regression analyses. ${ }^{+} p<.10 . * p<.05 . * * p<.01$.

second-order factor structures at Time 1 and Time 2 (Time 1: $\chi^{2}=23.70$; d.f. $=24$; $\mathrm{GFI}=.96 ; \mathrm{NFI}=.91 ; \mathrm{TLI}=1.00 ; \mathrm{CFI}=1.00 ; \mathrm{RMSEA}=.000 ; \mathrm{RMR}=.041 ;$ Time 2 : $\chi^{2}=25.66 ;$ d.f. $=24 ; \mathrm{GFI}=.96 ; \mathrm{NFI}=.90 ; \mathrm{TLI}=.99 ; \mathrm{CFI}=.99 ; \mathrm{RMSEA}=.024 ;$ $\mathrm{RMR}=.049$ ). Intercorrelations between the scales for both points of measurement are reported in Table 5. Table 6 displays item wordings and factor loadings. Next, we tested whether job crafting was distinct from, but correlated with, taking charge (Hypothesis 1b). We compared a model where taking charge was a distinct latent factor in the model (Model 1) with a model where we assigned the items from the takingcharge scale to the latent factor task crafting (Model 2). The rationale behind this model was that taking charge is a task-related, proactive behavior that might be similar to task crafting. The results revealed that job crafting was distinct from taking charge $\left(\Delta \chi^{2}=63.94 ; \Delta\right.$ d.f. $\left.=2, p<0.001, n=118\right)$. Correlations between the job crafting scales and taking charge were small and ranged from $r=.05$ to $r=.29$ (see Table 5). Hypothesis $1 \mathrm{~b}$ was supported. In sum, the CFAs showed that the three-dimensional second-order factor structure showed a good fit, and was distinct from related constructs. We also found - even if only partially - evidence for criterion-oriented 


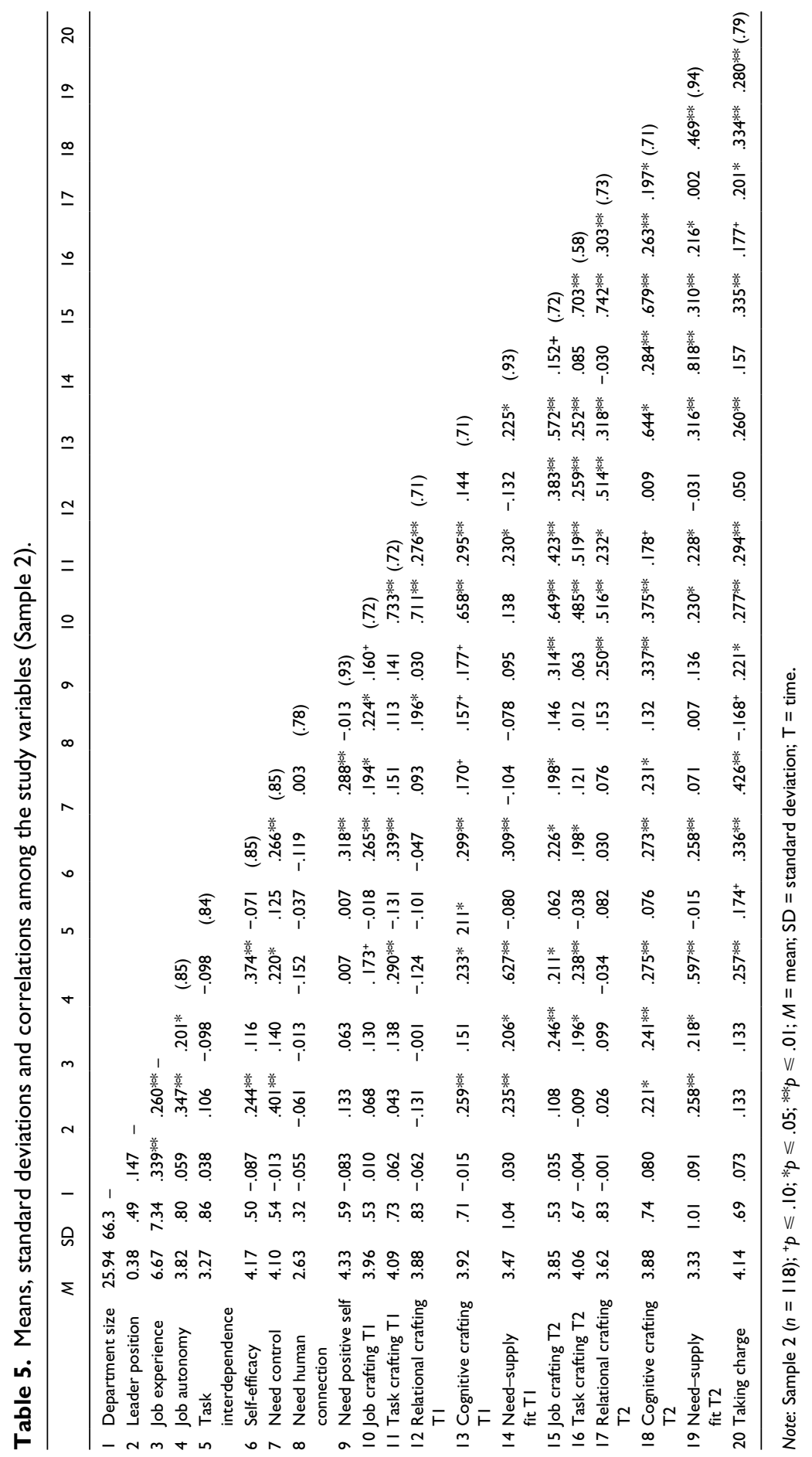


Table 6. Wording and factor loadings of the scale items for Sample I and Sample 2.

\begin{tabular}{|c|c|c|c|}
\hline Items & $\begin{array}{l}\text { Sample I } \\
(n=233)\end{array}$ & $\begin{array}{l}\text { Sample } 2 \\
(n=118) \mathrm{TI}\end{array}$ & $\begin{array}{l}\text { Sample } 2 \\
(n=118) \mathrm{T} 2\end{array}$ \\
\hline \multicolumn{4}{|l|}{$\begin{array}{l}\text { Task crafting: } \\
\text { So that the job I do suits me... }\end{array}$} \\
\hline I concentrate on specific tasks. & .63 & .65 & .37 \\
\hline I undertake or seek for additional tasks. & .82 & .70 & .74 \\
\hline \multicolumn{3}{|l|}{ Relational crafting: } & .61 \\
\hline $\begin{array}{l}\text { So that the job I do suits me... } \\
\text { I usually limit the amount of time I spend with } \\
\text { people I do not get along well with, and only } \\
\text { contact them for things that are absolutely } \\
\text { necessary. }\end{array}$ & .50 & .50 & .46 \\
\hline $\begin{array}{l}\text { I invest in relationships with people whom I } \\
\text { get along with the best. }\end{array}$ & .81 & .66 & .84 \\
\hline $\begin{array}{l}\text { I look for opportunities to work together with } \\
\text { people whom I get along well with at work. }\end{array}$ & .85 & .95 & .81 \\
\hline \multicolumn{4}{|l|}{$\begin{array}{l}\text { Cognitive crafting: } \\
\text { So that the job I do suits me... }\end{array}$} \\
\hline $\begin{array}{l}\text { I try to look upon the tasks and responsibilities } \\
\text { I have at work as having a deeper meaning than } \\
\text { is readily apparent. }\end{array}$ & .65 & .54 & .47 \\
\hline $\begin{array}{l}\text { I find personal meaning in my tasks and } \\
\text { responsibilities at work. }\end{array}$ & .88 & .77 & .83 \\
\hline $\begin{array}{l}\text { I view my tasks and responsibilities as being } \\
\text { more than just part of my job. }\end{array}$ & .78 & .73 & .71 \\
\hline Task crafting - second order load & .97 & .84 & .76 \\
\hline Relational crafting - second order load & .66 & .45 & .60 \\
\hline Cognitive crafting - second order load & .73 & .46 & .49 \\
\hline
\end{tabular}

Note: $T=$ time.

validity of our job crafting measure. For further analyses, we used the unweighted mean of all items for a composite measure of job crafting, as well as the unweighted means of the subscales.

\section{Antecedents of job crafting}

In Study 2, we tested our hypotheses by examining can do factors, reason to factors, work characteristics and work experience in relation to job crafting. Table 5 shows the means, standard deviations, intercorrelations and coefficient alphas of the study variables. A first inspection of the significant bivariate correlations between Time 1 predictors and Time 2 job crafting activities revealed that, as expected, self-efficacy was positively related to job crafting (composite, .211), task crafting (.238) and cognitive crafting (.273). There was no significant relationship with relational crafting. Need for control was associated, as expected, with job crafting (composite, .198), and cognitive crafting (.231), but not with task crafting and relational crafting. Need for positive self-image 
Table 7. Prediction of job crafting at Time 2 by antecedents assessed at Time I (hierarchical regression analyses).

\begin{tabular}{|c|c|c|c|c|c|c|c|c|}
\hline & \multicolumn{2}{|c|}{$\begin{array}{l}\text { Job crafting Time } 2 \\
\text { (composite score) }\end{array}$} & \multicolumn{2}{|c|}{$\begin{array}{l}\text { Changing task } \\
\text { boundaries Time } 2\end{array}$} & \multicolumn{2}{|c|}{$\begin{array}{l}\text { Changing } \\
\text { relational } \\
\text { boundaries Time } 2\end{array}$} & \multicolumn{2}{|c|}{$\begin{array}{l}\text { Changing cognitive } \\
\text { task boundaries } \\
\text { Time } 2\end{array}$} \\
\hline & $\beta$ & $\Delta R^{2}$ & $\beta$ & $\Delta R^{2}$ & $\beta$ & $\Delta R^{2}$ & $\beta$ & $\Delta R^{2}$ \\
\hline Step I (Time I) & & $.426 * * * *$ & & $.271 * * * *$ & & $.274 * * * *$ & & .424 \\
\hline Leader position & .059 & & -.027 & & .093 & & .033 & \\
\hline Department size & .033 & & -.032 & & .018 & & .084 & \\
\hline $\begin{array}{l}\text { Outcome at } \\
\text { Time I }\end{array}$ & $.645^{* * * *}$ & & $.522 * * *$ & & $.528 * * *$ & & $.637 * * *$ & \\
\hline Step 2 (Time I) & & .013 & & .014 & & .016 & & .016 \\
\hline Job autonomy & .101 & & .127 & & .019 & & .119 & \\
\hline $\begin{array}{l}\text { Task } \\
\text { interdependence }\end{array}$ & .080 & & .048 & & .130 & & -.048 & \\
\hline Step 3 (Time I) & & $.07 I^{*}$ & & .026 & & $.072^{*}$ & & $.072 * *$ \\
\hline Work experience & $.170 *$ & & $.172^{*}$ & & .090 & & .095 & \\
\hline Self-efficacy & -.076 & & -.010 & & -.021 & & -.023 & \\
\hline Need for control & -.018 & & .049 & & -.108 & & .058 & \\
\hline $\begin{array}{l}\text { Need for human } \\
\text { connection }\end{array}$ & .037 & & -.036 & & .069 & & .066 & \\
\hline $\begin{array}{l}\text { Need for positive } \\
\text { self-image }\end{array}$ & $.234^{* *}$ & & -.020 & & $.259 * *$ & & $.237^{* *}$ & \\
\hline Overall $F$ & & $11.128 * * *$ & & $4.840 * * * *$ & & $6.060^{\text {sotek }}$ & & $11.255^{* *}$ \\
\hline$R^{2}$ & & .510 & & .311 & & .362 & & .513 \\
\hline Adjusted $R^{2}$ & & .464 & & .247 & & .302 & & .467 \\
\hline
\end{tabular}

Note: Sample $2(n=1 \mid 8)$. The $\Delta R^{2}$ and $F$ values were derived from hierarchical regression analyses. $+p<.10 . * p<.05 . * * p<.01$.

showed the strongest correlations with job crafting activities (composite: .314; relational crafting, .250; cognitive crafting .337). Job autonomy correlated significantly with the composite measure of job crafting $(r=.211)$, task crafting $(r=.238)$, and cognitive crafting $(r=.275)$. Task interdependence had no significant relationships with job crafting. Work experience correlated significantly with job crafting (composite, .246), task crafting (.196) and cognitive crafting (.241), but not with relational crafting.

We used multiple hierarchical regression analyses to examine our hypotheses. The criterion variables were the Time 2 measures of task crafting, relational crafting, cognitive crafting, as well as the composite measure of job crafting. For each criterion variable, we entered the corresponding measure at Time 1. In the first step, we also included control variables (leader position, department size). In the second step, we entered the work characteristics (job autonomy, task interdependence), and in the third step, we examined work experience, can do factors (self-efficacy), and reason to factors (need for control, need for human connection, need for positive self-image). The results of these analyses are shown in Table 7.We stated that self-efficacy (Hypothesis 3) at Time 1 predicts an increase in job crafting at Time 2. This hypothesis was not supported. Individuals' reason to factors, in particular the need for positive self-image at Time 1, predicted an 
increase in job crafting activities from Time 1 to Time 2. Individuals who felt a need for positive self-image at Time 1 increased their job crafting (composite, $\beta=.34 ; p<.01$ ), relational crafting $(\beta=.26 ; p<.01)$ and cognitive crafting $(\beta=.24 ; p<.01)$, supporting Hypotheses $6 \mathrm{~b}$ and $\mathrm{c}$. Need for control and need for human connection had no significant relationships with job crafting at Time 2. Therefore, Hypotheses $4 \mathrm{a}-\mathrm{c}$ and Hypothesis 5 were not supported.

Hypotheses $7 \mathrm{a}-\mathrm{c}$ proposed that job autonomy predicts positively job crafting activities. Although job autonomy at Time 1 correlated positively with job crafting activities, the hierarchical regression analyses revealed no significant relationship after controlling for the respective outcomes at Time 1. Task interdependence (Hypotheses $8 \mathrm{a}-\mathrm{c}$ ), neither correlated with job crafting activities at Time 2 nor predicted an increase in job crafting activities in the hierarchical regression analyses. In support for Hypothesis 9, results revealed that the more work experience employees had the more job crafting activities at Time 2 they reported $(\beta=.17 ; p<.05)$, in particular crafting task boundaries $(\beta=.17$; $p<.05$ ), after we controlled for the respective outcome. Hypothesis 9 a was supported, but not Hypotheses $9 \mathrm{~b}$ and $\mathrm{c}$.

\section{Discussion}

The purpose of the present studies was to gain insight into antecedents of job crafting and to offer validation of a measure of job crafting based on the conceptualization of Wrzesniewski and Dutton (2001). Our results revealed that with substantial work experience, individuals were capable of crafting their jobs. Moreover, the need to maintain or create a positive self-image at work was the main reason to engage in job crafting.

Our confirmatory factor analyses on the two samples provided a good fit for a secondorder model with three first factors representing the data. In both studies, the three job crafting dimensions were positively correlated, and there was a substantial correlation between the three dimensions and the second-order factor. Therefore, the dimensions can be aggregated into a general construct (second-order factor), which reflects the common dimension of job crafting, whereby the three dimensions indicate which concrete behavior and cognitive activities individuals use to craft their jobs. As the type of crafting an individual chooses depends on personal and situational factors, research should assess all dimensions of job crafting.

Both studies showed that job crafting was related to, although different from, constructs such as personal initiative, taking charge and organizational citizenship behavior. Moreover, in line with the proposition of Wrzesniewski and Dutton (2001), job crafting - more specifically, cognitive crafting - predicted an increase in fit perceptions. This complements the study of Lu et al. (2014), which investigated relations between task crafting, relational crafting, and fit perceptions. However, our study did not replicate their result that the need-supplies fit increases when individuals crafted their social relations. First, it might be that in our study the time lag of two weeks was too short to observe changes in needs-supplies fit, which was quite stable in the present study. Thus, there was not much variance left that could be explained by job crafting. Second, it might be that it takes some time and effort until task crafting and relational crafting increases the needs-supplies fit. Consequences of task crafting and relational crafting are not 
totally under control of the job crafter. When individuals invest in relationships with colleagues whom they get along with the best, it might be that after a while, these relationships fail to develop according to initial expectations. Consequently, need-supplies fit does not improve. In a similar vein, changing tasks might result in unexpected side effects, such as conflicts with team members and increased workload, which do not increase the needs-supplies fit. Moreover, carrying out job crafting behaviors involves adaptive efforts (e.g. negotiation with the supervisor, trust building), as the study of Berg et al. (2010b) suggested. Depending on the result of these adjustments, job crafting will or will not increase the needs-supplies fit. Thus, the job crafting-fit relationship might be moderated by other factors, such as (un-)expected outcomes of crafting behaviors or adaptive moves (Berg et al., 2010b). By contrast, cognitive crafting and its consequences are more under individuals' control: By representing tasks at work in a different manner, individuals might focus on features of their job that fit with their needs.

There is also evidence for the reverse relationship between job crafting and fit (in which Time 1 fit predicts Time 2 job crafting). Person-environment fit theories such as the Minnesota Theory of Work Adjustment (Dawis and Lofquist, 1984) propose that individuals initially perceive a misfit with their work environment, which triggers reactive behaviors (e.g. learning) and active behaviors (e.g. altering tasks) needed to reestablish the fit. Future research should investigate both directions of the relationship between the three kinds of job crafting and fit in a longitudinal study with three waves in order to gain more insight into the dynamic relationship between job crafting and fit.

The article gives also insight into antecedents of job crafting. Study 2 highlighted the role of the self and its relationship with job crafting. An important predictor of job crafting was the need for positive self-image. This indicates that individuals who have the desire to create a positive image of themselves are more likely to engage in job crafting activities, and in particular, in crafting the social and cognitive boundaries of their job. This is in line with the theory of self-enhancement (Leary, 2007) and of self-assessment (Swann and Read, 1981), which propose that individuals sustain or enhance their selfview by shaping their social environment. However, in turn, the self-view depends to some extent on social interactions. Wrzesniewski et al. (2003) argued that in the work context, individuals receive cues from others, which directly impact the value ascribed by others to the self and the job. Thus, job crafting activities are self-oriented, but nonetheless also depend on social interactions at work. The results might indicate that theories about the self are a promising approach to predicting and explaining job crafting that are complementary to work design approaches, such as the job demands-resources model (Bakker and Demerouti, 2007).

The need for control did not predict an increase in job crafting at Time 2, but it correlated positively with job crafting at Time 2 , specifically cognitive crafting. As need for control was associated with the need for positive self-image, positive self-image was the stronger reason to engage in job crafting.

Need for human connection did not predict an increase in job crafting as well. There might be two possible explanations for this unexpected result. First, two contradictional processes might be stimulated when individuals experience a lack of human connection. On the one side, individuals who have an unsatisfied need to belong often feel sad, depressed and anxious, and show more avoidance motivation (Baumeister and Leary, 1995; Leary et al., 2006; Pillow et al., 2015), which in turn might hinder the engagement 


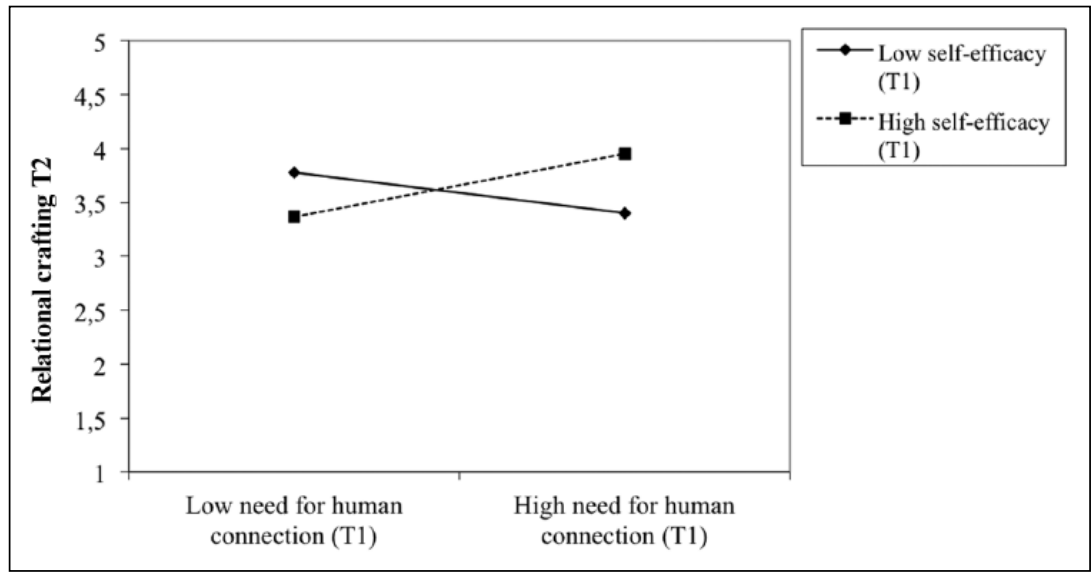

Figure 2. Interaction between need for human connection $x$ self-efficacy predicting relational crafting at Time 2 .

in job crafting behaviors. However, as we proposed in our hypotheses, on the other side it also seems likely that the unsatisfied need is a signal that stimulates the desire for change (e.g. Baumeister and Vohs, 2007; Carver and Scheier, 1990) and makes job crafting more likely. It might be that self-efficacy helps to overcome negative mood and worries. Individuals who have an unsatisfied need to belong and are in a negative, depressed mood, yet feel capable to meet the challenges at work, may cope with their negative mood and engage in relational crafting. We were able to test this post-hoc explanation with data from Study 2. We added the interaction between need for human connection and self-efficacy in a fourth step of the hierarchical regression analyses (see Table 7), and found a significant result $\left(\beta=.229, p<.0001 ; \Delta R^{2}=.071, p<.001\right)$. A higher need for human connection predicted an increase in relational crafting when self-efficacy was high ( $1 \mathrm{SD}$ above the mean, $z=0.231, t=2.506, p=0.013$; see Figure 2). A higher need for human connection was related to a decrease in relational crafting when self-efficacy was low (1 SD below the mean, $z=-0.269, t=-2.918, p=0.004$ ). Future research should identify further moderators of the relationship between the need for human connection and job crafting.

Another reason for the non-significant results of the relation between need for human connection and relational crafting might be that individuals satisfy their need in their private life, in particular when social relationships at work are less stable and reliable compared to those in one's private life (Baumeister and Leary, 1995). Colleagues at work might change often, or contact is less frequent. Consequently, behaviors that aim at the satisfaction of the need to belong in the work context might be reduced.

Although self-efficacy as a can do factor is a well-established predictor of proactive behavior, we found no direct, significant relationships with an increase in job crafting at Time 2. We found bivariate correlations with task crafting and cognitive crafting at Time 2 . Moreover, self-efficacy was a significant moderator in the association between need for human connection and an increase in relational crafting. This indicates that self-efficacy as a can do factor is an important prerequisite for implementing job crafting behaviors, 
but it does not alone initiate crafting behaviors in order to gain personal meaning. Future research on the can do factors of job crafting should identify the conditions under which work experience, self-efficacy and so forth contribute to job crafting.

We found that our proposed predictors explained the most variance in cognitive crafting change. This might be because crafting cognitive task boundaries is less effortful, and less risky, compared to behaviors that alter actual tasks and relationships at work. In addition, cognitive crafting might increase within a shorter time frame compared with behavioral crafting that might require some preparation and negotiation in advance. Furthermore, one can speculate whether cognitive crafting reflects not only a crafting activity but also a first phase in the job crafting process. After framing the job cognitively, individuals might then engage in behaviors that change tasks and social relationships. For example, the abovementioned hospital cleaner who sees her work as a means to help the patients rather than just to clean can craft her job cognitively, which may result in relational crafting by increasing interactions with patients and their families. We need a better theoretical understanding and more empirical data regarding how the job crafting process evolves. Process models of proactive behaviors (Grant and Ashford, 2008; Parker et al., 2010) that distinguished between psychological representation of a possible proactive action (e.g. anticipation of future states, planning) and concrete behaviors might be useful in directing further research.

Finally, job autonomy and task interdependence did not predict an increase in job crafting. Job autonomy was only correlated with task crafting and cognitive crafting at Time 2. It might be that the time lag of two weeks was too short for job autonomy to lead to an increase of job crafting activities. In addition, we found no significant relationships between task interdependence and job crafting. It might be that task interdependence can foster and hinder job crafting activities. For example, when working closely together in a team, employees are restricted in their opportunities to change task and social boundaries of their jobs on their own, but they may also have more opportunities to swap tasks among each other. In addition, as Berg et al. (2010b) suggested, task interdependence might impact the direction of crafting activities. High task interdependence might stimulate crafting behaviors that aim at parts of their work, which are most independent from those of others (see also Ghitulescu, 2013). Until now, research on job crafting in teams has been rare (for an exception, see Tims et al., 2013a). Future research should investigate under which conditions task interdependence among team members fosters or hinders crafting.

Work experience was related to an increase in job crafting from Time 1 to Time 2. Individuals who stay longer in their organization are socially more integrated and accepted. They may have accumulated knowledge about the organization and the job, which assists them changing their tasks. However, this knowledge does not seem to be sufficient enough to initiate relational crafting or cognitive crafting.

\section{Limitations}

First, all measures relied on self-report. However, Study 2 was a two-wave study separating the measurement of predictor and outcome variables to minimize the potential effects 
of common method bias. In addition to self-reported job crafting, researchers should explore supervisors' or colleagues' ratings of job crafting behaviors. However, in line with the reasoning of Wrzesniewski and Dutton (2001), we think that supervisors and colleagues may not necessarily notice when individuals craft their jobs. It is likely that the validity of other assessments of employees' job crafting activities depends heavily on the frequency of contact and on the opportunity to have access to the respective information. Second, we operationalized task crafting by focusing on or adding new tasks. We did not investigate reducing tasks, which would be an interesting future research issue. Moreover, although the confirmatory factor analyses provided a good fit of the measure, some factor loadings were low. Third, Cronbach's alpha for task crafting at Time 2 of Study 2 was quite low (.58). This indicates that the subscale is inconsistent and that the items should be reconsidered. However, in the other two measurements (Time 1 Study 2, Study 1), the reliability of task crafting was above.70. Future research will show whether this low reliability in one measurement was an exception or not. We cannot rule out that due to the low reliability, it was more difficult to predict change in task crafting from Time 1 to Time 2. Finally, we operationalized work experience with length in an organization. Strictly speaking, we do not know whether organizational tenure reflects knowledge about the organization, skills acquired on the job, or otherwise. Future research should investigate which type of knowledge (job-related, and/or organization-related) supports job crafting.

In sum, the studies showed that job crafting as a self-oriented proactive behavior was motivated by the need for positive self-image, and related to work experience. The need for human connection and self-efficacy did not predict job crafting components independently, but jointly: The need for human connection stimulated relational crafting when individuals were self-efficacious.

\section{Acknowledgements}

We thank Bettina Eibl, Sabine Hommelhoff, Inge Mäder and Teresa Müller for their insightful comments on an earlier draft of this article. A previous version of this article was presented at the 12th Annual Meeting of the Academy of Management, Boston, USA (2012).

\section{Funding}

This research received no specific grant from any funding agency in the public, commercial, or not-for-profit sectors.

\section{References}

Arbuckle JL (2007) AMOS (Version 7) [Computer software]. Chicago: SPSS.

Ashford SJ and Black JS (1996) Proactivity during organizational entry: A role of desire for control. Journal of Applied Psychology 81(2): 199-214.

Ashforth BE and Kreiner GE (1999) 'How can you do it?': Dirty work and the challenge of constructing a positive identity. Academy of Management Review 24(3): 413-434.

Bakker AB and Demerouti E (2007) The job demands-resources model: State of the art. Journal of Managerial Psychology 22(3): 309-328.

Bakker AB, Tims M and Derks D (2012) Proactive personality and job performance: The role of job crafting and work engagement. Human Relations 65(10): 1359-1378. 
Baumeister RF and Leary MR (1995) The need to belong: Desire for interpersonal attachments as a fundamental human motivation. Psychological Bulletin 117(3): 497-529.

Baumeister RF and Vohs KD (2007) Self-regulation, ego depletion, and motivation. Social and Personality Psychology Compass 1(1): 115-128.

Belschak FD and Den Hartog DN (2010) Pro-self, prosocial, and pro-organizational foci of proactive behaviour: Differential antecedents and consequences. Journal of Occupational \& Organizational Psychology 83(2): 475-498.

Berg JM, Dutton JE and Wrzesniewski A (2008) What is job crafting and why does it matter. Available at the website of Positive Organizational Scholarship (accessed on 15 April 2011).

Berg JM, Grant AM and Johnson V (2010a) When callings are calling: Crafting work and leisure in pursuit of unanswered occupational callings. Organization Science 21(5): 973994.

Berg JM, Wrzesniewski A and Dutton JE (2010b) Perceiving and responding to challenges in job crafting at different ranks: When proactivity requires adaptivity. Journal of Organizational Behavior 31(2/3): 158-186.

Bindl UK and Parker SK (2011) Proactive work behavior: Forward-thinking and change-oriented action in organizations. In: Zedeck S (ed.) APA Handbook of Industrial and Organizational Psychology, Volume 2: Selecting and Developing Members for the Organization. Washington, DC: American Psychological Association, 567-598.

Black JS and Ashford SJ (1995) Fitting in or making jobs fit: Factors affecting mode of adjustment for new hires. Human Relations 48(4): 421-437.

Burger JM and Cooper HM (1979) The desirability of control. Motivation and Emotion 3(4): 381-393.

Cable DM and DeRue DS (2002) The convergent and discriminant validity of subjective fit perceptions. Journal of Applied Psychology 87(5): 875-884.

Carver CS and Scheier MF (1990) Origins and functions of positive and negative affect: A controlprocess view. Psychological Review 97(1): 19-35.

Chen G, Gully SM and Eden D (2001) Validation of a new general self-efficacy scale. Organizational Research Methods 4(1): 62-83.

Crant JM (2000) Proactive behavior in organizations. Journal of Management 26(3): 435-462.

Dawis RV and Lofquist LH (1984) A Psychological Model of Work Adjustment. Minneapolis: University of Minnesota Press.

Demerouti E (2014) Design your own job through job crafting. European Psychologist 19(4): 237-247.

Fay D and Frese M (2001) The concept of personal initiative: An overview of validity studies. Human Performance 14(1): 97-124.

Frese M, Fay D, Hilburger T, et al. (1997) The concept of personal initiative: Operationalization, reliability and validity in two German samples. Journal of Occupational and Organizational Psychology 70(2): 139-161.

Frese M, Kring W, Soose A and Zempel J (1996) Personal initiative at work: Differences between East and West Germany. Academy of Management Journal 39(1): 37-63.

Gardner WL, Pickett CL and Brewer MB (2000) Social exclusion and selective memory: How the need to belong influences memory for social events. Personality and Social Psychology Bulletin 26(4): 486-496.

Gerbing DW and Hamilton JG (1996) Viability of exploratory factor analysis as a precursor to confirmatory factor analysis. Structural Equation Modeling 3(1): 62-72.

Ghitulescu BE (2006) Crafting tasks and relationships at work: Examining the antecedents and consequences of employee job crafting. Unpublished doctoral dissertation, University of Pittsburgh. 
Ghitulescu BE (2013) Making change happen: The impact of work context on adaptive and proactive behavior. Journal of Applied Behavioral Science 49(2): 206-245.

Gist M and Mitchell T (1992) Self-efficacy: A theoretical analysis of its determinants and malleability. Academy of Management Review 17(2): 183-211.

Grant AM and Ashford SJ (2008) The dynamics of proactivity at work. Research in Organizational Behavior 28(1): 3-34.

Greenberger DB (1981) Personal Control at Work: Its Conceptualization and Measurement. Technical Report, University of Wisconsin-Madison.

Greenberger DB, Strasser S, Cummings LL and Dunham RB (1989) The impact of personal control on performance and satisfaction. Organizational Behavior and Human Decision Processes 43(1): 29-51.

Hackman JR and Oldham GR (1976) Motivation through the design of work: Test of a theory. Organizational Behavior and Human Performance 16(2): 250-279.

Hahn VC and Dormann C (2013) The role of partners and children for employees' psychological detachment from work and well-being. Journal of Applied Psychology 98(1): 26-36.

Hornung S and Rousseau D (2007) Active on the job-proactive in change: How autonomy at work contributes to employee support for organizational change. Journal of Applied Behavioral Science 43: 401-426.

Humphrey SE, Nahrgang JD and Morgeson FP (2007) Integrating motivational, social, and contextual work design features: A meta-analytic of the summary and theoretical extension work design literature. Journal of Applied Psychology 92(5): 1332-1356.

Hurley AE, Scandura TA, Schriesheim CA, et al. (1997) Exploratory and confirmatory factor analysis: Guidelines, issues, and alternatives. Journal of Organizational Behavior 18(6): 667-683.

Leana C, Appelbaum E and Shevchuk I (2009) Work process and quality of care in early childhood education: The role of job crafting. Academy of Management Journal 52(6): 1169-1192.

Leary MR (2007) Motivational and emotional aspects of the self. Annual Review of Psychology 58(1): 317-344.

Leary MR, Kelly KM, Cottrell CA and Schreindorfer LS (2006) Construct validity of the need to belong scale: Mapping the nomological network. Journal of Personality Assessment 95(6): 610-624.

Lu C, Wang H, Lu J, et al. (2014) Does work engagement increase person-job fit? The role of job crafting and job insecurity. Journal of Vocational Behavior 84(2): 142-152.

Lyons P (2008) The crafting of jobs and individual differences. Journal of Business Psychology 23(1-2): 25-36.

McDonald S (2011)What you know or who you know? Occupation-specific work experience and job matching through social networks Social Science Research 40(6): 1664-1675.

Morrison EW and Phelps CC (1999) Taking charge at work: Extrarole efforts to initiate workplace change. Academy of Management Journal 42(4): 403-419.

Neff A, Niessen C, Sonnentag S and Unger D (2013) Expanding crossover research: The crossover of job-related self-efficacy within couples. Human Relations 66(6): 803-827.

Nielsen K and Abildgaard JS (2012) The development and validation of a job crafting measure for use with blue-collar workers. Work \& Stress 26(4): 365-384.

Ohly S and Fritz C (2007) Work characteristics, challenge appraisal, creativity, and proactive behavior: A multi-level study. Journal of Organizational Behavior 31(4): 543-565.

Organ DW (1988) Organizational Citizenship Behavior: The Good Soldier Syndrome. Lexington, MA: Lexington Books.

Parker SK, Bindl UK and Strauss K (2010) Making things happen: A model of proactive motivation. Journal of Management 36(4): 827-856. 
Parker SK, Williams HM and Turner N (2006) Modeling the antecedents of proactive behavior at work. Journal of Applied Psychology 91(3): 636-652.

Petrou P, Demerouti E, Peeters MCW, et al. (2012) Crafting a job on a daily basis: Contextual correlates and the link to work engagement. Journal of Organizational Behavior 33(8): $1120-1141$.

Pillow DR, Malone GP and Hale WJ (2015) The need to belong and its association with fully satisfying relationships: A tale of two measures. Personality and Individual Differences 74(1): 259-264.

Porras JI and Robertson PJ (1992) Organizational development: Theory, practice, and research. In: Dunnette MD and Hough LM (eds) Handbook of Industrial \& Organizational Psychology. Palo Alto, CA: Consulting Psychologists Press, 719-822.

Rego A, Souto S and Cunha MPE (2009) Does the need to belong moderate the relationship between perceptions of spirit of camaraderie and employees' happiness? Journal of Occupational Health Psychology 14(2): 148-164.

Schmidt FL, Hunter JE and Outerbridge AN (1986) Impact of job experience and ability on job knowledge, work sample performance, and supervisory ratings of performance. Journal of Applied Psychology 71(3): 432-439.

Scott WR (1987) Organizations: Rational, Natural, and Open Systems. Englewood Cliffs, NJ: Prentice Hall.

Semmer N, Zapf D and Dunckel H (1999) Instrument zur Stressbezogenen Tätigkeitsanalyse [Instrument for stress-oriented task-analysis (ISTA)]. In: Dunckel H (ed.) Handbuch psychologischer Arbeitsanalyseverfahren. Zürich: VDF, Hochschulverlag an der ETH Zürich, 179-204.

Sheldon KM and Gunz A (2009) Psychological needs as basic motives, not just experiential requirements. Journal of Personality 77(5): 1467-1492.

Slemp GR and Valla-Brodrick DA (2014) Optimising employee mental health: The relationship between intrinsic need satisfaction, job crafting, and employee well-being. Journal of Happiness Studies 15(4): 957-977.

Speier C and Frese M (1997) Generalized self-efficacy as a mediator and moderator between control and complexity at work and personal initiative: A longitudinal field study in East Germany. Human Performance 10(2): 171-192.

Staufenbiel T and Hartz C (2000) Organizational citizenship behavior: Entwicklung und erste Validierung eines Meßinstruments. Diagnostica 46(2): 73-83.

Sturges J (2012) Crafting a balance between work and home. Human Relations 65(12): 1539-1559.

Swann WB and Bosson JK (2010) Self and identity. In: Fiske ST, Gilbert DT and Lindzey G (eds) Handbook of Social Psychology. Hoboken, NJ: John Wiley \& Sons Inc., 589-628.

Swann WB and Read SJ (1981) Self-verification processes: How we sustain our self-conceptions. Journal of Experimental Social Psychology 17(4): 351-372.

Tafarodi RW and Swann WB (2001) Two-dimensional self-esteem: Theory and measurement. Personality and Individual Differences 31(5): 653-673.

Tims M and Bakker AB (2010) Job crafting: Towards a new model of individual job redesign. South African Journal of Industrial Psychology 36(2): 1-9.

Tims M, Bakker AB and Derks D (2012) Development and validation of the job crafting scale. Journal of Vocational Behavior 80(1): 173-186.

Tims M, Bakker AB and Derks D (2013a) The impact of job crafting on job demands, job resources, and well-being. Journal of Occupational Health Psychology 18(2): 230-240.

Tims M, Bakker AB and Derks D (2014) Daily job crafting and the self-efficacy-performance relationship. Journal of Managerial Psychology 29(5): 490-507. 
Tims M, Bakker AB, Derks D and Van Rhenen W (2013b) Job crafting at the team and individual level: Implications for work engagement and performance. Group \& Organization Management 38(4): 427-454.

Van den Heuvel M, Demerouti E, Bakker AB and Schaufeli WB (2010) Personal resources and work engagement in the face of change. In: Houdmont J and Leka S (eds) Contemporary Occupational Health Psychology: Global Perspectives on Research and Practice. Chichester: John Wiley \& Sons Ltd, 124-150.

Vallacher RR and Wegner DM (1987) What do people think they are doing? Action identification and human behavior. Psychological Review 94(1): 3-15.

Withey MJ and Cooper WH (1989) Predicting exit, voice, loyalty, and neglect. Administrative Science Quarterly 34(4): 521-539.

Wrzesniewski A and Dutton JE (2001) Crafting a job: Revisioning employees as active crafters of their work. Academy of Management Review 26(2): 179-201.

Wrzesniewski A, Dutton JE and Debebe G (2003) Interpersonal sensemaking and the meaning of work. In: Kramer RM and Staw BM (eds) Research in Organizational Behavior: An Annual Series of Analytical Essays and Critical Reviews, vol. 25. Oxford: Elsevier Science Ltd, 93-135.

Cornelia Niessen is Full Professor in Work and Organizational Psychology at the FriedrichAlexander University of Erlangen-Nürnberg, Germany. Dr Niessen's research interests are in the areas of adaptive performance, vitality, proactive behavior and aging at work. She has published in journals such as Journal of Applied Psychology, Journal of Organizational Behavior, Journal of Occupational Health Psychology, Human Relations, Journal of Vocational Behavior, Journal of Occupational and Organizational Psychology and Leadership Quarterly. [Email: cornelia. niessen@fau.de]

Daniela Weseler is a doctoral student at the Friedrich-Alexander University of Erlangen-Nürnberg, Germany. Her current research focuses on job crafting. She has published on men working in female-dominated occupations in Journal of Applied Social Psychology, Psychology of Men and Masculinity and Sex Roles. [Email: daniela.weseler@fau.de]

Petya Kostova currently works in the field of Learning and Development in Switzerland. She received her Diploma in Psychology from the University of Constance and holds a MA/MBA in General Management. Her research interests focus on job crafting, meaning of work and proactive behavior. [Email: pe_kostova@yahoo.com] 